Article

\title{
Food Policy Councils as Loci for Practising Food Democracy? Insights from the Case of Oldenburg, Germany
}

\author{
Annelie Sieveking \\ Institute of Sustainability Governance, Leuphana University of Lueneburg, 21335 Lueneburg, Germany; \\ E-Mail: sieveking@leuphana.de
}

Submitted: 14 March 2019 | Accepted: 6 July 2019 | Published: 28 October 2019

\begin{abstract}
In the highly concentrated and consolidated 21st century food systems, a broad range of stakeholders are rarely involved in food-related decision-making processes. One innovative institutional response is the establishment of food policy councils (FPCs). These institutions are often initiated by civil society actors and seek to transform prevailing agro-industrial food systems. They aim to raise awareness for alternative practises of food consumption and production, and they try to shape food policies at different governance levels. FPCs have been acclaimed for their democratic potential in the past. This study uses the five key dimensions of food democracy identified by Hassanein (2008) to assess the ways in which FPCs might represent loci for practising food democracy. This is achieved by taking one of the first FPCs in Germany as an example. During a two-year study period (2016-2018), the emergence of the FPC Oldenburg was studied through participant observations, semi-structured interviews, and document analysis. Data analysis reveals examples of, as well as challenges related to, all five dimensions of food democracy. In addition, the in-depth analysis of the case also illustrates the importance of taking additional aspects into account, i.e., openness and transparency. Looking at an additional dimension of food democracy, which covers the "How?" of the deliberative process, might allow for a more nuanced analysis of the democratic potential of food initiatives in the future.
\end{abstract}

\section{Keywords}

civil society; empowerment; food citizenship; food democracy; food policy council

\section{Issue}

This article is part of the issue "New Perspectives on Food Democracy" edited by Basil Bornemann (University of Basel, Switzerland) and Sabine Weiland (Université Catholique de Lille, France).

(C) 2019 by the author; licensee Cogitatio (Lisbon, Portugal). This article is licensed under a Creative Commons Attribution 4.0 International License (CC BY).

\section{Introduction}

In the highly concentrated and consolidated 21st century food system, citizen participation in food-related decision-making processes in Western democracies has mainly been limited to indirect control by representative democratic institutions. These processes have also been influenced by professional organizations and interest groups. It is perhaps the perceived outsized influence of some of these groups which has contributed to a lack of support for policy measures and a legitimacy crisis of the representative democratic system (Renting, Schermer, \& Rossi, 2012, pp. 296-297). More specifically, food citizenship-i.e., the involvement of citizens in food-related decision-making processes-has been ad- versely affected by four developments: the corporate control of the food chain, the limited information available to consumers about products, the manipulation of supermarkets to increase sales, and a proliferation of deskilling convenience food (Welsh \& MacRae, 1998, p. 243). These developments notwithstanding, the food system affects people's daily life in a very intimate way, which might provide a strong motivation and opportunity for individuals to reclaim their citizenship.

In the context of diminishing food citizenship, "civil society-based initiatives become an important source of innovation through social learning, the building of new capacities and by creating 'space to manoeuvre' for organizing food production, distribution, and consumption differently" (Renting et al., 2012, p. 298). These ini- 
tiatives reflect new relationships between, on the one hand, civil society and markets (active involvement in re-constructing alternative systems of food provisioning) and, on the other hand, between civil society and public institutions (civic engagement in shaping public opinion, culture, institutions and policies by communication, lobbying, and political activism; Renting et al., 2012, p. 300). Alternative food networks are but one example of the new connections which have emerged in recent decades (Goodman, Dupuis, \& Goodman, 2012).

The emerging phenomenon of food policy councils (FPCs) seems to address both new linkages: These initiatives are mainly initiated by civil society (Harper et al., 2009, p. 25) and are striving to bring together stakeholders from a variety of sectors related to food, including public institutions and business. Their main aim is to influence local food policies, but under their umbrella, new food markets also emerge, e.g., community-supported agriculture. They comprise various representatives from the different segments of the food system community (e.g., members of community organizations, civil society organizations, the retail sector, and nutritional education) in order to discuss, coordinate, and influence the local food policy (Stierand, 2014, p. 169). FPCs can be regarded as concrete examples of a deliberate attempt to develop the practise of food democracy (Allen, 2010, p. 301; Hassanein, 2003, p. 79). Carlson and Chappell (2015) emphasize FPCs' potentially unique role in connecting the "How?" of deliberative processes with the "What?" of food access and justice. They furthermore stress FPCs' high potential for being "inclusive, transparent, and intentional spaces for dialogue" (p. 15). A tentative assessment of the democratic potential of FPCs based on a power-based concept of complex democracy is given by Bornemann and Weiland (2019).

Originating in the US in the early 1980s, the number of FPCs in North America has been increasing ever since, especially over the last decade. Based on a comprehensive survey, the latest Food Policy Report refers to 341 active councils in North America and Canada (Bassarab, Santo, \& Palmer, 2019, p. 3). One well-known example is the Toronto FPC in Canada, which has also been discussed in terms of food democracy. Providing a mechanism for people's active participation in shaping the food system was an explicit goal of the Toronto FPC from its very beginning (Welsh \& MacRae, 1998, p. 238). Its initial set up as a round table with people of differing political views and a variety of food system sectors (p. 250) is still characteristic of many FPCs. In contrast to North America, FPCs are a rather new institutional phenomenon in Europe, especially in Germany. The first two FPCs formed in 2016 in the cities of Cologne and Berlin. During the period of this study, four more FPCs were established in German cities (Frankfurt, Dresden, Oldenburg and Kiel). Currently, there are around 40 more FPC initiatives in Germany and German-speaking countries planning to form FPCs. To the best of my knowledge, no research has been done on these initiatives and their potential regarding food democracy.
This article seeks to disentangle a variety of aspects that potentially make FPCs loci for practising food democracy. Participation of citizens in the food system requires places where citizens have the opportunity to express and negotiate their interests and concerns. To study different expressions of food citizenship, it is necessary to move beyond simply conceptualizing food as a commodity and people as consumers (Welsh \& MacRae, 1998, p. 240). Along these lines, this study aims to apply and refine existing conceptualizations of food democracy. The analytical framework developed by Hassanein, consisting of five key dimensions of food democracy, is meant to serve as a lens for analysing food initiatives and their democratic characteristics (Hassanein, 2008, p. 306).

This lens was applied to the emerging phenomenon of FPCs in Germany. The aim was to investigate one of the first German FPCs, the exemplary case of the FPC in Oldenburg (a city with approximately 167,000 inhabitants in Lower Saxony) in terms of food democracy. The process of its formation was studied in a qualitative case study between 2016 and 2018. The analysis of the emerging FPC Oldenburg (1) allows for a more nuanced understanding of the particular case and (2) represents a key step in conceptualizing how FPCs, in general, can contribute to a strengthening of food citizenship. By analysing the phenomenon of FPCs from a food democracy perspective and by extending Hassanein's analytical framework by adding additional aspects to be taken into account, this study contributes to existing research on food democracy both empirically and conceptually.

After an introduction to the food democracy concept and Hassanein's operationalization in particular (Section 2), the methodological approach for studying the phenomenon of FPCs in terms of food democracy will be explained in greater detail (Section 3). In the subsequent section, the results of the analysis will be presented vis-à-vis each food democracy dimension identified by Hassanein (Section 4). In the following section, the findings of this study will be discussed in the broader context of emerging FPCs in Germany and regarding the practise and concept of food democracy more generally (Section 5). The article concludes with a short summary and considerations concerning further research.

\section{Conceptual Background}

The food democracy concept is based on the assumption that food is more than a commodity and that people are more than consumers (Hassanein, 2003, p. 79; Welsh \& MacRae, 1998, p. 239). In contrast to the ongoing process of diminishing food citizenship mentioned above, food democracy is about citizens having the power to determine agro-food policies and practises locally, regionally, nationally, and globally: The concept strives for active citizen participation in shaping the food system (Hassanein, 2003, p. 79). Food democracy, therefore, challenges the anti-democratic forces of control and claims the rights and responsibilities of citizens to participate in decision- 
making instead (Hassanein, 2003, p. 83). According to Hassanein, every incremental step of pragmatic politics should be oriented towards the vision of an ecologically sound, economically viable, and socially just system of food and agriculture. As achieving sustainability involves conflict over values, food democracy considers active participation and political engagement as necessary prerequisites if solutions to the dominant system are to be achieved (Hassanein, 2003, pp. 84-85). For Hassanein, active citizen participation is needed to achieve sustainability. In turn, citizen participation as such does not necessarily lead to more sustainable outcomes (Newig, Challies, Jager, Kochskaemper, \& Adzersen, 2017).

One basic principle of substantive democracy is that people should have an equal opportunity to participate in decisions that affect them. Taking this notion of democracy seriously, the core of the food democracy concept "is the idea that all people participate actively and meaningfully in shaping food systems" (Hassanein, 2008, p. 289). In order to build and extend the theory of food democracy, Hassanein suggests an analytical framework consisting of five key dimensions of food democracy (Hassanein, 2008, pp. 290-291):

1. Collaborating towards food system sustainability;

2. Becoming knowledgeable about food and the food system;

3. Sharing ideas about the food system with others;

4. Developing efficacy concerning food and the food system; and

5. Acquiring an orientation towards the community good.

The first dimension (i.e., collaboration towards food system sustainability) refers to the need for partnerships which may increase citizens' power and which may thus make a difference beyond individual decisions and actions. Effecting changes towards sustainability requires strong coalitions that involve differing interests (Hassanein, 2008, p. 290). Becoming knowledgeable about food and the food system is an additional dimension of food democracy because knowledge is considered a prerequisite for meaningful citizen participation: "Hence, food democracy means that people have a broad knowledge of the food system and its various facets" (Hassanein, 2008, p. 290). Furthermore, being engaged in deliberation and having shared ideas (dimension 3) are assumed to help people make better decisions for both themselves and others: Ongoing discussion and deliberation are therefore key to food democracy as they help citizens clarify issues and scrutinize their own values. The fourth dimension of food democracy (developing efficacy concerning food and the food system) relates to citizens' ability to determine their relationship to food and to address and solve community problems instead of just being passive consumers. Lastly, acquiring an orientation of the community good implies a willingness to recognize the value of mutual support and interdepen- dence, and to promote the well-being of the community. This sense of, and care for, the public good is central to food democracy and requires citizens to go beyond their self-interest (Hassanein, 2008, pp. 290-291).

Hassanein's attempt to operationalize the concept of food democracy was one the first and remains highly influential. It can help researchers and practitioners identify strengths and weaknesses in alternative agri-food initiatives concerning their democratic characteristics (Hassanein, 2008, p. 306).

\section{Methodology}

The recently founded FPC in Oldenburg, Lower Saxony, serves as an exemplary case of the emerging phenomenon of FPCs in Germany. The formation process of one of the first FPCs in Germany was studied between April 2016 and April 2018 in a qualitative case study, including participant observations, semi-structured stakeholder interviews, and document analysis. The rich dataset of eight participant observations, nine interviews, and a huge number of documents (e.g., internal protocols) allows for a detailed analysis of the FPC initiative. Data collection followed an iterative process between data collection and analysis that was carefully documented. All interviews were recorded, transcribed, and transferred to the software Atlas.ti for coding. All data collected from the case is in German and the quotations in this article are my translations. Additional data on other emerging FPC initiatives were collected during my participation in the first and second networking congress between FPC initiatives in German-speaking countries in 2017 and 2018.

Taking the Oldenburg case as an example to provide initial answers to the question of how FPCs might serve as loci for practising food democracy, this study considers the whole dataset on the emerging FPC but focusses on a crucial event during the formation process (the so-called pre-formation). The so-called pre-formation marks the beginning of the phase during the emergence, in which the core initiators - after a long period of preparationpresented their ideas in public and inspired a couple of new people to join their activities prior the official formation. This particular occasion, therefore, allows for a comprehensive illustration of how the five food democracy dimensions identified by Hassanein played out in the case. Data analysis was guided by five sub-questions covering the five food democracy dimensions.

This pre-formation event took place in June 2017, one and a half years after the initiative had started their activities and four months before the council was officially established. This event was organized by the coordinating group, consisting of ten volunteers who prepared the formation of the council. At that time, the initiative's activities were solely based on voluntary work although the members had already started applying for funding. Around 30 participants joined the pre-formation event. The main aim of the event was to found different com- 
mittees (thematic working groups), representing the basis of the future FPC. After an initial plenary session, the participants gathered in small groups to elaborate on the visions and tasks for the future committees of the council (see Figure 1). After a short presentation of each group in another plenary session, there was an informal slot dedicated to exchange between the participants. Afterwards, the coordinating group presented the next steps towards the formation of the council four months later.

\section{Results}

The results will be presented in five subsections, each covering one dimension of food democracy. As outlined in the methods section, the analysis takes the entire dataset of the case study into account but illustrates key findings with examples from the pre-formation event.

\subsection{Collective Action towards Sustainability: To What Extent Does the Initiative Strive for Collective Action towards Sustainability?}

The Oldenburg FPC initiative's activities started with a first workshop in April 2016 in the format of a so-called "Political Soup Pot," where people gather to talk about how to take action while preparing a communal meal. As one event during the city's Future Days, an annual series of events related to sustainable living, this workshop provided an opportunity to exchange ideas among interested citizens about how to nourish Oldenburg in the future. Local initiatives that are "following new paths regarding a socially and ecologically just food production and consumption" (invitation flyer) were invited to present their projects, e.g., on community gardens or food sharing. In small group discussions around topics collectively selected in the plenary, such as food waste or education, the workshop participants exchanged ideas about how to move forward. One group discussed the idea of establishing an FPC in the city of Oldenburg in order to give the pre-existing transformative efforts a common voice.

After this event, a core group of about ten volunteers prepared the formation of the FPC and launched the preformation stage one year later. During this event, four different committees (see Figure 1) formed and the participants started planning future activities. The committees on different food-related topics had the main function of bringing together pre-existing transformative activities in Oldenburg and creating a network. These committees were meant to be open for everyone interested in participating based on their interests and resources. More formally, the 15 members of the representative body of the council (see Figure 1), equally covering civil society, public administration/politics, and business were formally

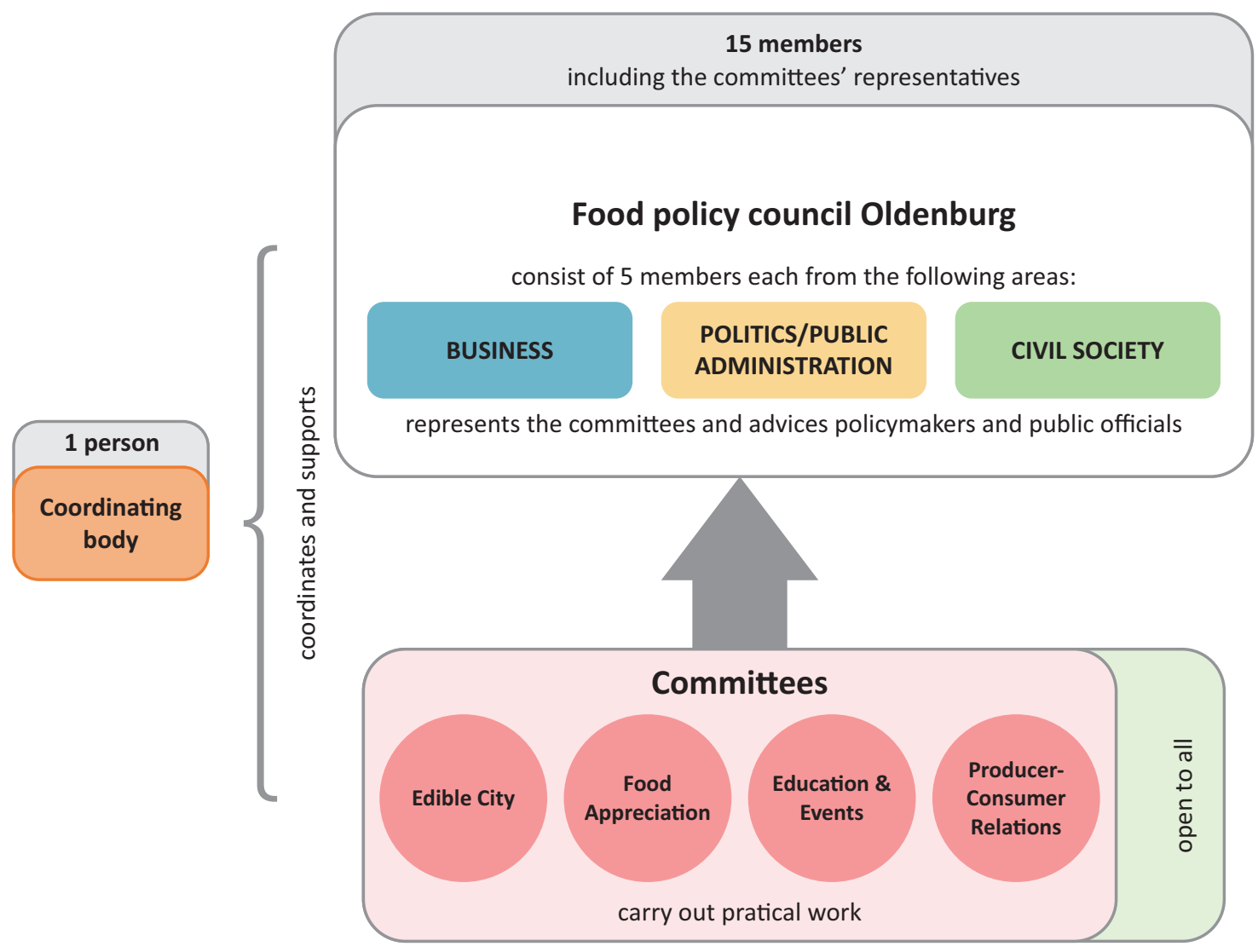

Figure 1. Structure of the emerging FPC initiative in Oldenburg, presented at the formation event (by Desirée Diering, my translation). 
elected for an initial period of two years shortly before the official establishment in October 2017. At that stage of the emergence of the FPC, the volunteers successfully acquired public funding for a part-time coordinator for the first year following the formation. All meetings, activities, and events of the initiative were open to the public and announced in advance on the homepage.

At the pre-formation event in June 2017, the coordinating group presented the motto they had agreed upon as a baseline for the future work of the FPC: "Together for sustainable nutrition in the region," including the elements "regional, fair, need-oriented, selfdetermined, and ecological" (presentation at the preformation event). During this presentation, the initiators also outlined the need for dialogue between different stakeholders, e.g., producers and consumers, but also processors, retailers, and public officials. They also emphasized the ideal of having all of these groups being involved in the council, either as a representative or as an active member in one of the committees. The FPC initiative strives for collective action towards sustainability based on a broad group of stakeholders agreeing on a shared set of values regarding more sustainable food production and consumption.

In the emergence phase, the initiative's members were not able to agree on a more detailed version of their vision. Apart from disagreements, they also did not feel that they should determine specific criteria prior to the official formation without being able to take future members into account. After the council had been established, the representative body started a discussion about specific criteria and installed a working group to develop these in greater detail.

\subsection{Knowledge about Food and the Food System: How Does the FPC Initiative Support Individual Learning about Food and the Food System?}

In its early stages, the FPC initiative offered numerous opportunities for learning about the food system, simply by making it possible for individuals to get in touch with one another. Coming together on this multi-stakeholder platform, individuals who were ready to collaboratively strive for a transformation of the current system, encountered a number of different aspects of the food system. This diversity of perspectives was also a result of different ways to be involved, ranging from voluntary engagements in existing food initiatives, e.g., food sharing, to formal professional work, e.g., as a restaurant owner or employee of a retail company. The initiative mostly focused on the local food system, but dissatisfaction with the globalised food system often framed their activities. At the first workshop, for example, a food activist from South Africa, Zayaan Khan, gave a presentation about current challenges in the global food system and the need for local responses.

At the pre-formation event roughly a year later, the coordinating group defined education and the raising of awareness as central tasks of the initiative. The members presented examples of food-related events in Oldenburg where they informed the public about the initiative's goals (e.g., a sustainability week at the local university or a food truck event). On these occasions, the group members tried to make people think about food issues, for example with a memory game on the $\mathrm{CO}_{2}$ emissions of different vegetables (presentation pre-formation event). The committees, as initiated at the pre-formation, particularly supported self-organized learning in the four different thematic areas (see Figure 1) chosen by participants. Despite huge interest in the work of the Education and Events Committee, it was initially difficult to find people willing to take on responsibility because of limited resources. In the following, the committees' activities ranged from excursions to farms in the region, harvesting and processing locally grown food to workshops in schools. These activities provided learning opportunities about how to enact alternatives to the predominant methods of food production and consumption in daily life.

Despite many activities being undertaken during the initial phase, at times it was still difficult to keep all the committees alive. This is why the FPC turned the committees into more concrete and manageable projects shortly after the end of the study period.

\subsection{Sharing Ideas with Others: How Does the FPC Initiative Enable Discussion and Deliberation?}

In its emerging phase, the FPC initiative provided space for discussion and deliberation in various ways. Internally, the coordinating group was organized on a grassroots basis, implying a commitment to consensus and openness to new members. In practise, decisions were often prepared by a small group of people (e.g., the formulation of the initiative's aims or a concept for an event), which were then discussed and agreed upon in a plenary session (Interview 2). This practise implied that some people were more involved in certain steps than others; however, they always fed the results back into the whole group for comments and took decisions collectively to try to find a consensus. Majority voting was only rarely used. Someone always took minutes of the meetings so people were able to follow what had been discussed. In the course of their activities, the group distributed certain tasks to individual members (e.g., the facilitation of their regular meetings). This decision in particular facilitated smooth meetings and a more structured setting for discussing contested issues. After the official formation, protocols were made public on the initiative's homepage.

Regarding external communication, the group members approached a huge number of people from different backgrounds (e.g., the mayor or different parties) and also participated in public food-related events, such as panel discussions with representatives from the conventional farmers' organization where they were also con- 
fronted with those who did not share their vision of sustainability. At the pre-formation event, the coordinating group announced dialogue between different stakeholders as one of the initiative's central tasks. As with the other events they had organized and as with their regular meetings, they asked the participants to introduce themselves. Additionally, the organizers explicitly dedicated certain time slots to the informal exchange of ideas (e.g., after each committee presented the ideas previously elaborated in the small group discussions).

As time went on, it became increasingly difficult for the members to monitor their activities (Internal Meeting 23). Even though the initiative tried to have regular reports from each committee in the representative body's meetings, they did not always have this update due to a lack of presence or other topics being given greater priority. For newcomers, it was sometimes not clear whom they should talk to. Once, for example, a woman came to the representative's body meeting to report on a potentially interesting topic for the initiative but was then sent directly to the Edible City Committee.

\subsection{Efficacy with Respect to Food and the Food System: What Kind of Opportunities Does the FPC Initiative Provide for Experiencing Capacities to Act and Actually Having an Effect?}

The emerging FPC initiative was explicitly aimed at establishing new structures to allow individual citizens to participate: "I think we firstly need to learn democracy, to really talk and listen to each other and then becoming engaged at local level," as one interviewee pointed out when talking about the initiative's motto "Together for sustainable nutrition in the region" (Interview 7). The group also referred to self-determination as an important part of the realization of their vision (presentation pre-formation event). In the course of their activities, they created a variety of opportunities for experiencing capacities to act and to actually have an effect. On the one hand, citizens were always invited to join the committees and the activities undertaken (e.g., a bike tour to orchards in the city). On the other hand, the coordinating group always tried to organize their events according to their values and were, although being limited financially, always able to offer high-quality organic food due to donations from regional companies and their networking activities. In this sense, their activities provided a number of examples of how people can actually make a difference.

As regards to influencing policymakers and public officials, the initiative's members-despite many disappointments in the beginning-also experienced cases where they actually had an impact, e.g., the minister of food and agriculture becoming the FPC initiative's patron, the positive approval of a funding request, or the invitation to be part of a working group on improving the city's school catering. A strong motivator to go ahead with the actual establishment of the council was the strong reso- nance manifested in new people joining the group after the pre-formation event. As one interviewee said: "After a long period of discussion, also including phases of internal difficulties manifested in less capacities for preparing the event, we just needed such a success to go ahead" (Interview 7).

\subsection{Orientation towards the Community Good: To What Extent Does the FPC Initiative Encourage Individuals to Go beyond Their Self-Interest and Care about the Public Good?}

In the emerging FPC initiative, there was a general orientation towards collective action as outlined in Section 4.1. As a result of their holistic approach "Together for sustainable nutrition in the region," being part of the initiative as such required an interest in food as a public good. The members of the coordinating team joined the initiative because of dissatisfaction with the current system of food production and consumption, e.g., the lost connection between producers and consumers (Interview 3 ) or decreasing food skills among children (Interview 4). In the Edible City Committee, orientation towards the community good became maybe the most obvious, e.g., when thinking about how urban areas could be used for planting crop plants in collaboration with the city. In the Producer-Consumer Relations Committee, participants were introduced to a recently founded communitysupported agriculture initiative. This approach points exactly to the aspect of mutual support and interdependence between food producers and consumers. Additionally, the committee members organized several excursions to farms in the region. Here, participants were able to get in touch with farmers and to develop a better understanding of food production patterns. Internally, many members of the coordinating group used their individual skills for the good of the initiative (e.g., moderation, writing, or presentation skills).

At some point, many volunteers felt overwhelmed by the number of tasks and it became obvious that a staff coordinator was needed to support them. Several members also quit the group because they were no longer able to help due to other obligations. And among those who stayed, there was a constant feeling of doing too much for the initiative at the expense of their private life (clearly articulated by Interviewee 9). This situation improved when the initiative received funding to hire a part-time coordinator after the official formation of the council.

\section{Discussion}

The analysis of the emerging FPC initiative in terms of food democracy elucidates a broad spectrum of aspects that potentially make this case and comparable cases loci for practising food democracy. The analysis also reveals challenges related to the five dimensions. In the following section, the results of the case will be dis- 
cussed and contextualized in the broader landscape of the first German FPCs, which have been established in different cities during the study period (Cologne, Berlin, Frankfurt, Dresden, Kiel) as well as the numerous initiatives which were planning to form at that time and participated in the networking congresses of emerging initiatives in German-speaking countries in 2017 and 2018. Building on these reflections, implications for the practise and the concept of food democracy and FPCs' potential to democratise the food system will be discussed.

\subsection{Contextualizing the Case of the Oldenburg FPC}

Building on its broad membership and its multi-faceted activities, the emerging Oldenburg FPC can be interpreted as an example of a civil society initiative trying to establish new relationships between civil society and public institutions as well as new relationships between civil society and business (Renting et al., 2012). Indeed, the FPC Oldenburg did attract a variety of stakeholders in its emerging phase, e.g., people from all three targeted societal realms (civil society, public administration/politics and business) who became members of its representative body, as was also the case in Cologne. The FPC in Berlin, to give another example, also approached and attracted a variety of stakeholders in its emerging phase, but this initiative did not want certain groups to become members of the FPC (e.g., policymakers and public officials). Despite differences in member composition, all emerging initiatives build on the idea of bringing together a diversity of stakeholders in order to foster collective action towards sustainability (dimension one).

The in-depth analysis of the Oldenburg case based on Hassanein's dimensions illustrated in various ways how an emerging FPC can serve as a locus for developing a practise of food democracy (Allen, 2010) by offering opportunities for learning, sharing ideas, experiencing efficacy, and strengthening a sense of care for the community good. Despite a general focus on the local, involving experts from abroad seems to be a learning strategy used in the emerging German FPC movement. Having an international guest at the first event as in the Oldenburg case seems to be an exception and might be explained by the professional background of the initiator, who worked at a development NGO. Already during the first networking congress in 2017, however, international guests from Brazil, Canada, the UK, and the US played an important role by sharing their knowledge and experience with the emerging initiatives in Germany.

Raising awareness of food system issues more generally seems to be a central topic for all initiatives that were established during the study period as reflected in corresponding committees or working groups dedicated to educational activities. Despite a huge interest in that topic, it was initially difficult to implement the activities of the Education and Events Committee in the Oldenburg case because of a continual lack of personnel. As dealing with limited and shifting personnel is a crucial topic for many groups of volunteers, it might also be helpful to learn from initiatives at similar stages. Another emerging FPC initiative in Germany, for example, institutionalized continuous learning opportunities by starting their regular meetings with a short input on a specific topic (conversation second networking congress 2018). Such an approach might be appropriate for emerging FPCs and similar initiatives because it ensures ongoing mutual learning and provides an opportunity to step back from the timeconsuming discussion of everyday operations.

Regarding the provision of opportunities for discussion and deliberation (dimension three), all emerging initiatives have to negotiate how to communicate with each other (e.g., in their regular meetings). In the Oldenburg case, designating a moderator for their meetings represented a crucial step in structuring their internal culture of deliberation and becoming more efficient. While the group members emphasized the positive effects (i.e., an improved flow of their meetings), attributing the moderator's role to group members is challenging and can be problematic because of personal stakes in the content under deliberation and a certain power to shape the outcome of the discussion. One solution to this role conflict might be to hire professional moderators as the organizers of the first networking congress between initiatives in Germany and German-speaking countries did. Other emerging initiatives decided to rotate the moderator's role in regular meetings. This approach allows all members to gain experience of being responsible for the process and is also applicable in the case of a lack of will or budget to hire professionals.

As the chosen structure of the Oldenburg FPC (a representative body, a coordinating team and committees) resulted in some gaps in terms of information flow, the people involved in the initiative currently rethink the structures they established and plan to have a regular plenary similar to the FPC initiative in Berlin. This format is assumed to allow for a more regular and direct sharing of ideas and projects (conversation networking congress 2018). Formats that allow sharing ideas are increasingly important for FPC initiatives that try to remain open towards new ideas and developments in their communities. These open formats might also serve as a tool for integrating new members, a concern of many emerging initiatives, which was also discussed during the first networking congress.

The emerging FPC initiative in Oldenburg provided a number of opportunities for experiencing one's actions actually having an effect (dimension four). Next to more tangible results of individual engagement such as having donated organic food at their events, for experiencing actually having an impact, it seemed essential to convince other people to join or support the initiative. The strong resonance, especially during the pre-formation event, indicated a broad interest among diverse stakeholders to shape the current food system. Instead, fluctuation of membership and varying degrees of involvement led to frustration regarding efficacy. The dilemma of not 
wanting to overburden volunteers while at the same being a reliable organization seems to be a typical phenomenon in groups of volunteers (Turinsky \& Nowicka, 2019, p. 261). As all emerging FPC initiatives mainly build on voluntary work, it remains a constant challenge to join forces to have an impact, which, in turn, increases motivation to go ahead.

As regards to the Oldenburg initiative's effects in the public sphere, being invited to an official working group on how to improve the city's school catering is relevant because this offer to participate implies being heard and acknowledged by public officials, at least to a certain extent. Improving public catering is also on the agenda of all other German FPCs that formed during the study period. The FPC Frankfurt, for example, is currently also part of a city's working group. This FPC is running a pilot project demonstrating that improving school meals within the current budget is possible (FPC Frankfurt, 2019). At a well-attended working group meeting during the second networking congress in 2018, it also became clear that improving public catering seems to be an area where FPCs in the early stages try to have an effect in their communities.

While FPC initiatives might raise awareness of food as a collective good in policy-making processes, they also provide many opportunities for citizens to develop a sense of care for food as a public good. The analysis of the Oldenburg FPC illustrated this with different examples, e.g., harvesting fruits from orchards or planting crops in urban areas. The initiative's variety of topics and activities seems to resonate with many people. This may also be the case because, in the FPC, people find a space where they can combine personal interests (e.g., in gardening or educating people) with an orientation towards the community good. Furthermore, preexisting private initiatives for the community good can potentially gain more visibility through FPC initiatives, e.g., community gardens.

\subsection{Implications for the Practise and the Concept of Food Democracy}

Applying Hassanein's analytical framework to the Oldenburg case and its contextualisation within the broader context of pioneer initiatives in Germany demonstrated FPCs' potential to act as loci for developing a practise of food democracy in terms of the five dimensions. Despite several challenges and problems, all dimensions seem to become manifested in the emerging institutional phenomenon of FPCs. In this sense, the emergence of FPCs seems to be promising, suggesting a recent strengthening of food democracy despite the ongoing trends which tend to diminish food citizenship (Welsh \& MacRae, 1998, p. 243).

The manifestations of the five food democracy dimensions in this study also demonstrate that the framework suggested by Hassanein seems to capture general aspects of food democracy that are relevant beyond the particular initiative she was studying when identifying the five dimensions. In this sense, this study offers a certain validation of her framework. Looking for greater specificity of the food democracy concept through practical exploration (Hassanein, 2008, p. 289), the insights from the case of the Oldenburg FPC potentially also elucidate avenues for further theoretical elaboration of the food democracy concept. Hassanein acknowledges the importance of processes and basic principles of substantive democracy (Hassanein, 2008, p. 289), but these aspects are not explicitly addressed in the five dimensions. Drawing on Carlson and Chappell's understanding of FPCs as playing a potentially unique role in connecting the "How?" of deliberative processes with the "What?" of food access and justice (Carlson \& Chappell, 2015, p. 15), I argue that more process-oriented aspects should also be reflected in an analytical framework identifying characteristics of food democracy. The case of the Oldenburg FPC clearly demonstrates that the how of deliberative processes matters.

In the emerging FPC initiative, both striving for transparency and openness turned out to be central working principles. Regarding transparency, the members always took minutes of the meetings and made them available online so everyone could follow their activities. At the pre-formation event, when the council initiators launched the committees, the main requirement for the committees was to work transparently (presentation preformation event). This process criterion of transparency is closely linked to the second criterion to add, namely openness. As the group of volunteers always invited everyone to participate in the events they launched and their meetings were open to the public, the initiative can also be interpreted as inclusive compared to other food initiatives or interest groups which promote a particular interest and represent only a small group of people.

Openness and transparency appeared to be particularly relevant in the case of the Oldenburg FPC because conflicts in the emergence phase could often be attributed to situations in which information flows were interrupted or when it was not clear whether members or committees were entirely open about their actions or motivations. As a result, the initiative agreed to follow certain procedures (e.g., taking minutes or issuing open invitations to their events). The aspect of openness towards a broad spectrum of stakeholders, perspectives, and opinions is particularly relevant for multistakeholder platforms such as FPCs. Openness as a working principle, however, seems to be fundamental to food democracy more generally as an open mind could be regarded as a prerequisite for sharing ideas and learning from each other (dimensions two and three).

Openness vis-à-vis members and perspectives to be included in a civil society group, however, can also make the process of agreeing on certain venues and projects more difficult. Given the diversity of actors involved during the emergence of the FPC in Oldenburg, it is not surprising that they were unable to agree on the criteria to 
specify their vision in the emergence phase. Managing to remain vague, by having agreed on a general baseline understanding, can also be regarded as a means to remain open and supports the role of FPCs as multi-stakeholder platforms. The FPC Berlin, in contrast, being less open in terms of not including policymakers and public officials as members of their initiative, launched a list of demands to the government concerning the implementation of a local food strategy roughly a year after its formation, stressing more FPC's roles as advocates for particular interests. This example illustrates different degrees of openness vis-à-vis members and perspectives to be included even within the emerging FPC movement in Germany.

This study suggests that food democracy goes beyond the five dimensions identified by Hassanein. The case of FPCs demonstrates that the how of the deliberative process needs to be taken into account when studying concrete expressions of food citizenship. Although there is certainly more refinement needed regarding different manifestations of deliberative processes in different kinds of initiatives beyond FPCs, aspects related to the how of the deliberative process, e.g., transparency and openness should be considered in an analytical framework designed for studying the practise of food democracy. In their study on state-driven participation processes, Baldy and Kruse (2019) also identified transparent processes for deliberating ideas as a key category of food democray.

\subsection{FPCs' Potential to Democratise the Food System}

FPCs provide an example of bottom-up democratization dynamics because they are mostly initiated by civil society. Their approach to collaboration across sectors and their aim to shape food policies, however, needs support from policymakers and public officials. Because of FPCs' orientation towards food as a public good, public support, including the funding of FPC initiatives, seems appropriate. Providing a space where practising democracy can take place requires time and resources as illustrated in the case study. If FPCs are to become recognized spaces of deliberation, there needs to be public support for providing opportunities for meaningful participation in all five key food democracy dimensions as well as for ensuring processes based on substantive democracy (e.g., transparency and openness).

Given their recent emergence, it is not yet possible to assess FPCs' impact on food-related policymaking in Germany. Having representatives from FPC initiatives at municipal working groups for improving a city's school catering can be seen as a first opportunity for advocating for the initiatives' beliefs (e.g., more organic and more regionally produced food) in policy-making processes. FPC initiatives are able to negotiate based on a more comprehensive orientation towards the public good in contrast to stakeholders, such as organic farmers, who directly profit from a higher proportion of organic food being in the city's school catering. Such an involvement in policymaking might be expanded to other working groups or political committees concerned with food issues. Improving food systems by providing information for policy decision-making is one of the central tasks of FPCs (Clayton, Frattaroli, Palmer, \& Pollack, 2015, p. 9). This information is less specific, and possibly less biased than that provided by those advocacy groups focused on more specific concerns.

Despite reaching out to three societal realms (civil society, business, public officials, and policymakers), the exemplary case studied here did not equally represent the food system's sectors. Farmers, for example, were seldom present at the initiative's events, while the food business stakeholder group of the representative body included only one farmer. The need for a stronger involvement of farmers was articulated (e.g., Interview 1) and discussed (e.g., Internal Meeting 12) but not achieved in the initial period of the FPC initiative. This lack of farmer involvement is typical for the phenomenon of FPCs: In the US, FPC members mostly represent the production, distribution, and consumption sectors (Harper et al., 2009, p. 24), but particularly at the local level, the agricultural sector appears to be underrepresented (Mooney, Tanaka, \& Ciciurkaite, 2014, p. 238). Bassarab, Clark, Santo, and Palmer (2019) show that membership composition significantly influences the policy priorities of FPCs.

The potential for democratising the food system through FPCs could be assessed by who is represented in these councils. Considering that most FPCs in Germany, but also elsewhere, are initiated by civil society and primarily build on volunteers, FPCs mainly rely on those who are willing to become part of FPCs. Trying to cover different societal realms as in the case of the Oldenburg FPC is just one approach to think about member composition. Another attempt would be the approach referred to above (i.e., to have all food system sectors represented), which is often the case in FPCs initiated through government policy in the US. A recent study on representation in a public FPC in the US, however, demonstrated that representation by design and representation in practise varies considerably, for example in terms of attendance of meetings and agenda-setting (Koski, Siddiki, Sadiq, \& Carboni, 2016). Their first attempt to identify factors that limit substantive representation refers e.g., to restrictive process norms, lack of structure or mission clarity and unequal resources (2016, p. 16). These findings support the argument of paying more attention to the process of how FPCs and similar initiatives practise food democracy in their day-to-day operations (e.g., regarding transparency and openness as suggested by the analysis of the Oldenburg case studied here). Any design concerning representation in FPCs should be crucially examined regarding representation in practise.

The potential for FPCs to democratise the food system should however not only be judged on who is represented and how initiatives are trying to strive for equal representation through certain working principles. By 
involving citizens in decision-making processes and in other activities shaping the food system, FPCs might play an important role in empowering citizens' capacity to act. By offering different ways to participate, FPCs might also serve as an important tool concerning the legitimacy crises representative democracies are currently facing. Participation in decision-making in democratic systems is, however, not an alternative to political representation and expertise, but acts a complement to them (Fung, 2006, p. 66).

Diverse advisory councils such as FPCs - not limited to one stakeholder group but integrating citizens from various backgrounds-might represent an important tool for citizen participation in representative democracies more generally. The need for local platforms that bridge diverse forms of knowledge and expertise, has also recently been discussed in the broader context of innovations for sustainability (Perry, Patel, Bretzer, \& Polk, 2018). Similar to other community-based food initiatives such as Urban Gardening, FPCs seem to provide the opportunity and space in which citizens can get involved and collaborate across different interests and perspectives. These experiences might strengthen citizens' democratic capacity (Mclvor \& Hale, 2015, p. 738).

\section{Conclusions}

This study applied Hassanein's five key dimensions of food democracy to FPCs, an emerging phenomenon that has been acclaimed for its democratic potential. In order to allow for a thorough analysis and to provide concrete examples of how these dimensions work in practise, a case study approach was chosen. Data analysis revealed that the FPC in Oldenburg, Germany, during its emerging phase provided a number of opportunities for learning, for sharing ideas, for experiencing capacities to act, and for developing a sense of care for food as a public good. The results also revealed that the initiative in Oldenburg faced several challenges related to Hassanein's key dimensions (e.g., joining forces for having an impact or creating regular spaces for sharing ideas). As the discussion revealed, these aspects seem to be relevant for other emerging FPC initiatives in Germany as well. Still, it would be desirable to have a more comprehensive survey of how these dimensions are covered by more established FPCs in different parts of the world. The analysis of the case of the Oldenburg FPC also revealed that additional aspects related to the how of deliberative democracy (e.g., openness and transparency) need to be taken into account when conceptualizing food democracy. A critical assessment of how initiatives beyond FPCs practise transparency and openness when inviting citizens to shape the food system might further our understanding of this additional dimension. The extension of Hassanein's framework by this additional dimension covering the how of deliberative processes might allow for more nuanced analyses of alternative agri-food initiatives in terms of food democracy in the future.

\section{Acknowledgments}

This research was supported by the Volkswagen Foundation and the Lower Saxony Ministry for Science and Culture funded project 'Leverage Points for Sustainable Transformations: Institutions, People and Knowledge' (Grant Number A112269). I would like to thank all the interviewees for the time they dedicated to this study and my student assistants Mira Bodynek and Theresa Brand for their support in data documentation and analysis. I also would like to thank two anonymous reviewers and the special issue editors for their helpful comments on earlier versions of the manuscript.

\section{Conflict of Interests}

The author declares no conflict of interests.

\section{References}

Allen, P. (2010). Realizing justice in local food systems. Cambridge Journal of Regions, Economy and Society, 3(2), 295-308. https://doi.org/10.1093/cjres/rsq015

Baldy, J., \& Kruse, S. (2019). Food democracy from the top down? State-driven participation processes for local food system transformations towards sustainability. Politics and Governance, 7(4), 68-80.

Bassarab, K., Clark, J. K., Santo, R., \& Palmer, A. (2019). Finding our way to food democracy: Lessons from U.S. Food Policy Council governance. Politics and Governance, 7(4), 32-47.

Bassarab, K., Santo, R., \& Palmer, A. (2019). Food Policy Council report 2018. Retrieved from http://www. foodpolicynetworks.org/food-policy-resources

Bornemann, B., \& Weiland, S. (2019). Empowering people: Democratising the food system? Exploring the democratic potential of food-related empowerment forms. Politics and Governance, 7(4), 105-118.

Carlson, B. J., \& Chappell, M. J. (2015). Deepening food democracy. Minneapolis, MN: Institute for Agriculture and Trade Policy.

Clayton, M. L., Frattaroli, S., Palmer, A., \& Pollack, K. M. (2015). The role of partnerships in U.S. Food Policy Council policy activities. PLOS ONE, 10(4), e0122870. https://doi.org/10.1371/journal.pone.0122870

Food Policy Council Frankfurt. (2019). Informationen über Arbeitskreise [Information on working groups]. Ernährungsrat Frankfurt. Retrieved from https://ernaehrungsrat-frankfurt.de/arbeitskreise/ main-mittagessen

Fung, A. (2006). Varieties of participation in complex governance. Public Administration Review, 66, 66-75.

Goodman, D., Dupuis, E. M., \& Goodman, M. K. (2012). Alternative food networks: Knowledge, practice and politics. London and New York, NY: Routledge. https://doi.org/10.4324/9780203804520

Harper, A., Shattuck, A., Holt-Giménez, E., Wolf, A., Workman, M., Clare-roth, P., . . Strong, D. (2009). 
Food Policy Councils: Lessons learned. Oakland, CA: Food First Institute for Food and Policy. Retrieved from https://foodfirst.org/publication/foodpolicy-councils-lessons-learned

Hassanein, N. (2003). Practicing food democracy: A pragmatic politics of transformation. Journal of $R u$ ral Studies, 19(1), 77-86. https://doi.org/10.1016/ S0743-0167(02)00041-4

Hassanein, N. (2008). Locating food democracy: Theoretical and practical ingredients. Journal of Hunger \& Environmental Nutrition, 3(2/3), 286-308. https:// doi.org/10.1080/19320240802244215

Koski, C., Siddiki, S., Sadiq, A.-A., \& Carboni, J. (2016). Representation in collaborative governance: A case study of a Food Policy Council. The American Review of Public Administration, 48(4), 359-373. https://doi.org/ $10.1177 / 0275074016678683$

Mclvor, D. W., \& Hale, J. (2015). Urban agriculture and the prospects for deep democracy. Agriculture and Human Values, 32(4), 727-741. https://doi.org/10. 1007/s10460-015-9588-9

Mooney, P. H., Tanaka, K., \& Ciciurkaite, G. (2014). Food Policy Council movement in North America: A convergence of alternative local agrifood interests? In D. H. Constance, M.-C. Renard, \& M. G. Rivera-Ferre (Eds.), Alternative agrifood movements: Patterns of convergence and divergence (pp. 229-255). Bingley: Emerald. https://doi.org/10.1108/S1057192220140000021023

Newig, J., Challies, E., Jager, N. W., Kochskaemper, E.,
\& Adzersen, A. (2017). The environmental performance of participatory and collaborative governance: A framework of causal mechanisms. Policy Studies Journal, 46, 269-297. https://doi.org/10.1111/psj. 12209

Perry, B., Patel, Z., Bretzer, Y. N., \& Polk, M. (2018). Organising for co-production: Local interaction platforms for urban sustainability. Politics and Governance, 6(1), 189-198. https://doi.org/10.17645/pag. v6i1.1228

Renting, H., Schermer, M., \& Rossi, A. (2012). Building food democracy: Exploring civic food networks and newly emerging forms of food citizenship. International Journal of Sociology of Agriculture and Food, 19(3), 289-307.

Stierand, P. (2014). Speiseräume. Die Ernährungswende beginnt in der Stadt [Food spaces. Cities as a starting point for transforming food systems]. Munich: Oekom Verlag.

Turinsky, T., \& Nowicka, M. (2019). Volunteer, citizen, human: Volunteer work between cosmopolitan ideal and institutional routine. In M. Feischmidt, L. Pries, \& C. Cantat (Eds.), Refugee protection and civil society in Europe (pp. 243-268). Cham: Palgrave Macmillan.

Welsh, J., \& MacRae, R. (1998). Food citizenship and community food security: Lessons from Toronto, Canada. Canadian Journal of Development Studies/Revue Canadienne d'Etudes du Développement, 19(4), 237-255. https://doi.org/10.1080/02255189. 1998.9669786

\section{About the Author}

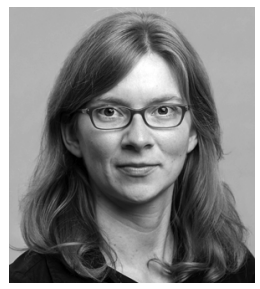

Annelie Sieveking is a PhD student at the Institute of Sustainability Governance at Leuphana University of Lueneburg in Germany. She holds an MSc in sustainability science and a BA in political science/educational science. Her research interests include the role of institutional settings, social innovations, and societal values in the context of transformations towards sustainability. In her cumulative PhD project, she investigates food policy councils as potential levers for sustainability transformation. 